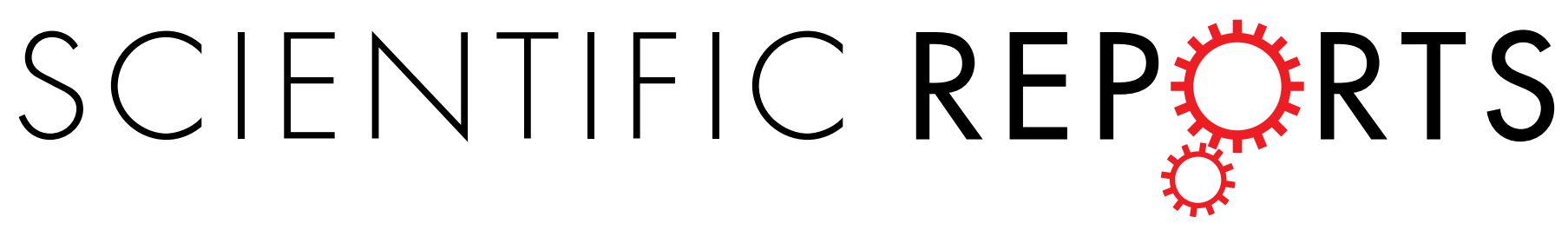

\title{
Corrigendum: The impact of resveratrol and hydrogen peroxide on muscle cell plasticity shows a dose-dependent interaction
}

\section{Alessandra Bosutti \& Hans Degens}

Scientific Reports 5:8093; doi: 10.1038/srep08093; published online 28 January 2015; updated 17 July 2015 This Article contains errors in Figure 4. In Figure 4a, the contrast image for the 'DM' group under 'Total myosin ATPase activity' is incorrect. In Figure 4b, the contrast images for the 'RS $40 \mu \mathrm{M}$ ' and 'RS $60 \mu \mathrm{M}$ ' group under 'Myosin type1 ATPase activity' are also incorrect.

Additionally, the Article contains errors in Figure 5b: the phase contrast images in the second panel under conditions ' $\mathrm{H}_{2} \mathrm{O}_{2}+\mathrm{RS} 10 \mu \mathrm{M}$ ' and ' $\mathrm{H}_{2} \mathrm{O}_{2}+\mathrm{RS} 20 \mu \mathrm{M}$ ' are incorrect.

The correct Figure 4 and $5 \mathrm{~b}$ appear below as Figure 1 and Figure 2 respectively.

a.

RS 24 h

Total myosin ATPase activity

\section{Myosin type1 ATPase activity}

b.

Myosin type1 ATPase activity

RS $48 \mathrm{~h}$

Total myosin ATPase activity
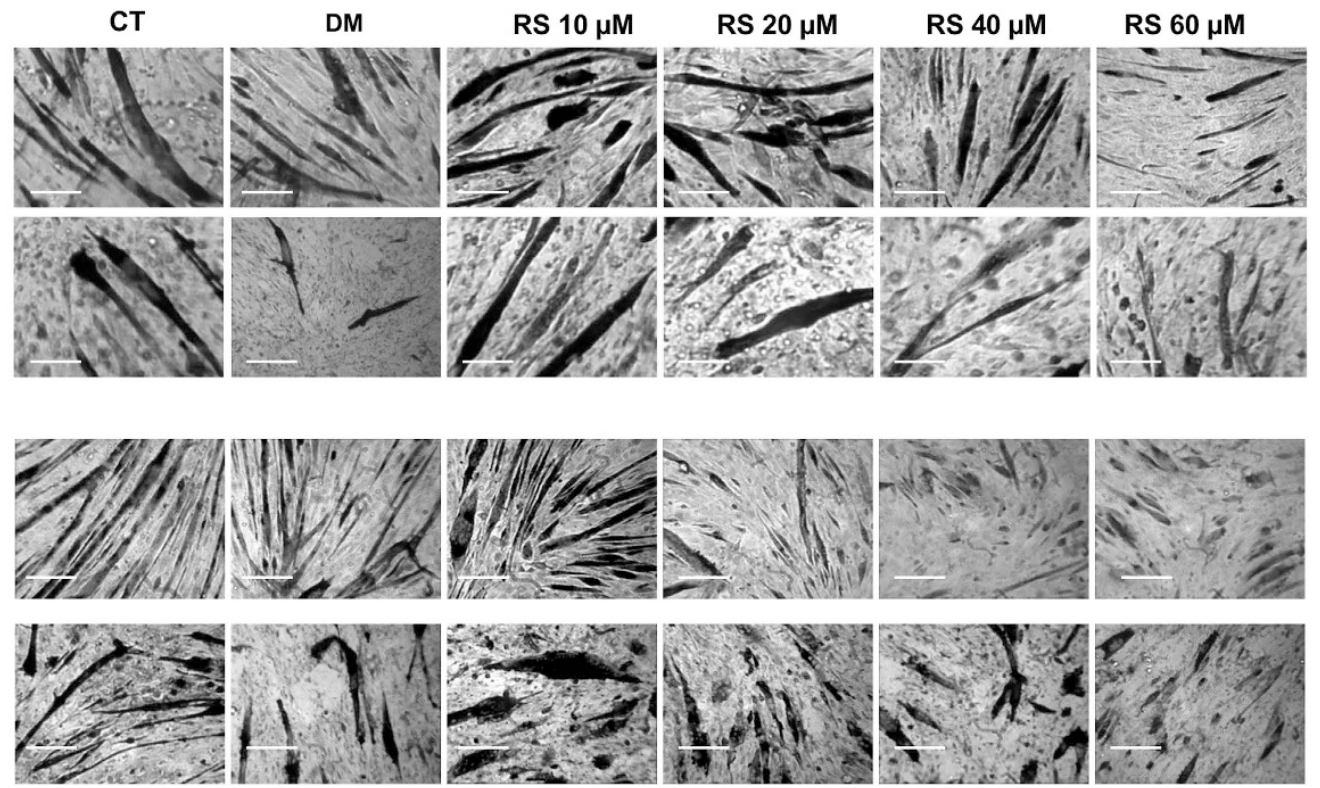

Figure 1. 


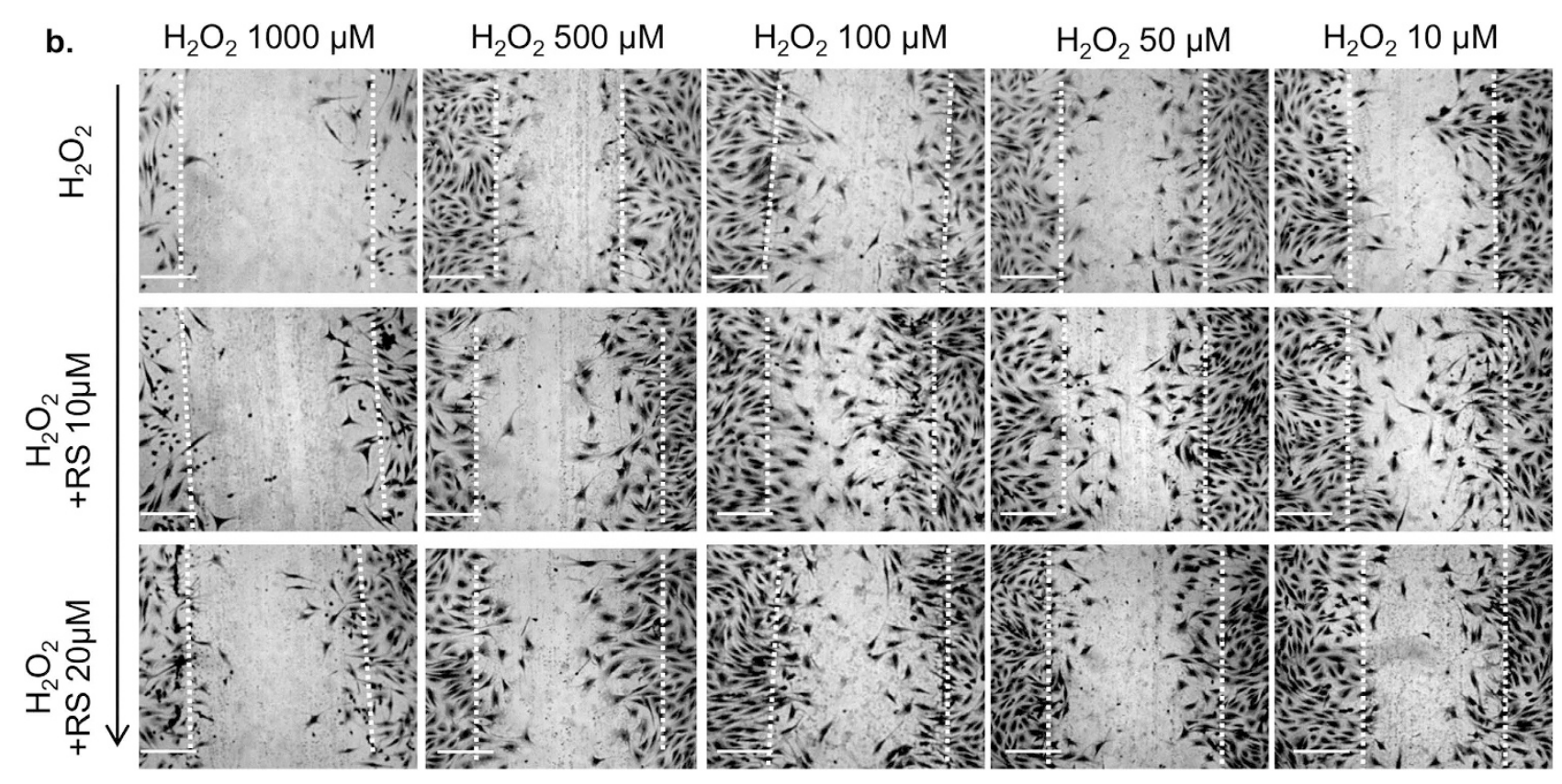

Figure 2. 